\title{
Stability versus Fluidity of Adolescent Romantic and Sexual Attraction and the Role of Religiosity: A Longitudinal Assessment in Two Independent Samples of Croatian Adolescents
}

Cohen, Nicole; Becker, Inga; Štulhofer, Aleksandar

Source / Izvornik: Archives of Sexual Behavior, 2020, -

Journal article, Accepted version

Rad u časopisu, Završna verzija rukopisa prihvaćena za objavljivanje (postprint)

https://doi.org/10.1007/s10508-020-01713-y

Permanent link / Trajna poveznica: https://urn.nsk.hr/urn:nbn:hr:131:991548

Rights / Prava: In copyright/Zaštićeno autorskim pravom.

Download date / Datum preuzimanja: 2023-04-26

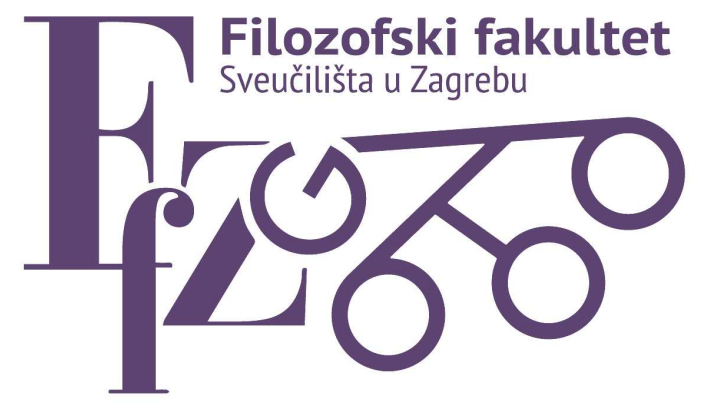

Repository / Repozitorij:

ODRAZ - open repository of the University of Zagreb Faculty of Humanities and Social Sciences
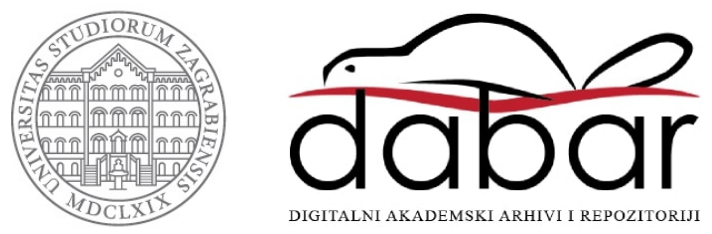
Stability vs. Fluidity of Adolescent Romantic and Sexual Attraction and the Role

\section{Religiosity: A Longitudinal Assessment in Two Independent Samples of Croatian}

\section{Adolescents}

Nicole Cohen, ${ }^{1}$ Inga Becker, ${ }^{2}$ Aleksandar Štulhofer ${ }^{3}$

${ }^{1}$ Department of Psychology, University of Kansas, Lawrence, KS 66046-7556, USA

${ }^{2}$ Department of Child and Adolescent Psychiatry, Psychosomatics and Psychotherapy, University Medical Center Hamburg-Eppendorf, Hamburg, Germany

${ }^{3}$ Department. of Sociology, Faculty of Humanities and Social Sciences, University of Zagreb, Zagreb, Croatia

\section{Address for Correspondence:}

Nicole L. Cohen

Department of Psychology,

1415 Jayhawk Blvd., University of Kansas,

Lawrence, Kansas 66046-7556

Telephone: 513-673-5520

E-mail: nlcohen@ku.edu

\section{Acknowledgements:}

The study has been funded by the Croatian Science foundation (grant \#9221). Additional funding was provided by Atlantic Grupa, d.d., Zagreb 
Stability vs. Fluidity of Adolescent Romantic and Sexual Attraction and the Role of Religiosity: A Longitudinal Assessment in Two Independent Samples of Croatian Adolescents 


\begin{abstract}
The manner in which individuals report their sexual attraction, self-label their sexual identity, or behave in sexual situations can vary over time, and especially adolescents may change their reported sexual attraction or sexual orientation identity over the course of their development. It is important to better understand the social factors that may influence these changes, such as one's religiosity. The present study thus aimed to assess the fluidity of adolescent romantic and sexual attraction over time, and to explore the role of religiosity in this dynamic using two independent panel samples of Croatian high-school students $(N=849$ and $N=995)$. Response items for sexual and romantic attraction were categorized based on the Kinsey scale, and religiosity was assessed with a standard one-item indicator. Results demonstrated that changes in attraction were substantially more prevalent among non-exclusively heterosexual participants compared to exclusively heterosexual participants in both panels. Although more female than male adolescents reported non-heterosexual attraction, gender differences in attraction fluidity were inconsistent. Religiosity was associated with initial sexual attraction (more religious individuals were more likely to report exclusively heterosexual attraction), but not with changes in romantic and sexual attraction over time. Given that the understanding of adolescent sexual development can play an important role in reducing their vulnerability to sexual risk taking, stigmatization, and abuse, this study's findings have relevance for teachers, parents, and counselors working with adolescents, and in particular for sexual minority youth.
\end{abstract}

Key Words: Adolescents; sexual fluidity; religiosity; sexual attraction; sexual orientation 


\section{INTRODUCTION}

Sexual and romantic attraction is one important component of sexual orientation, which further entails aspects of identity and behavior (Institute of Medicine, 2011). Sexual attraction is measured by how individuals acknowledge their feelings towards individuals of the same or other sex, and this may differ from self-labeling or identifying as "heterosexual" or "homosexual" or something else entirely (Diamond, 2003). Furthermore, the manner in which individuals report their sexual attraction, self-label their sexual identity, or behave in sexual situations can vary over time (Diamond \& Savin-Williams, 2000; Hu, Xu, \& Tornello, 2016). For example, both adults and young people may report feelings of sexual attraction that do not align with their sexual orientation identity (Katz-Wise, 2015) or may change their reported sexual attraction over the course of their development (Ott, Corliss, Wypij, Rosario, \& Austin, 2011).

Although a substantial amount of research has examined changes in sexual orientation identity among adolescents, few studies have examined changes in sexual and romantic attraction. The existing research has primarily been conducted in the United States, and has focused on young adulthood - a time period that may not capture when shifts in sexual attraction are most likely to occur. In addition, findings related to gender differences in fluidity have been inconsistent, with some findings demonstrating that it is more common among young women compared to men, and other findings demonstrating it is just as common among young men (Diamond, 2008; 2016; Everett, 2015). Finally, some research suggests that attitudes and cognitions may influence stability of sexual attraction (Katz-Wise \& Hyde, 2015), and religiosity has been associated with expression of sexual attraction among adults (Scheitle \& Wolf, 2018).

\section{Sexual Fluidity in Adolescence}


There is evidence that one's sexual attraction or sexual orientation identity may be particularly prone to instability during adolescence and among sexual minority groups (Ott et al., 2011; Rosario, Schrimshaw, Hunter, \& Braun, 2006; Savin-Williams \& Cohen, 2007). For example, one study of LGB youth and young adults (14-21 years old) found that $28 \%$ of participants did not endorse a stable sexual attraction over a one-year period (Rosario et al., 2006). Other studies have found similar percentages, with adolescents shifting from a same-sex to other-sex attraction and vice versa (Savin-Williams \& Ream, 2007; Savin-Williams et al., 2012). This instability of sexual attraction may lead to changes in sexual orientation identity, which has been referred to as sexual mobility or fluidity (Diamond, 2003; Everett, 2015; KatzWise \& Hyde, 2015; Ott et al., 2011; Savin-Williams, Joyner, \& Rieger, 2012). Most research shows that the process of sexual orientation development occurs between 14 and 21 years of age (Perrin, 2002; Savin-Williams \& Diamond, 2000). Shifts in sexual orientation identity mainly occur throughout the period of late adolescence and emerging adulthood (Ott et al., 2011), whereas changes in sexual attraction often precede the changes in sexual orientation identity (Savin-Williams \& Diamond, 2000).

Most existing longitudinal studies on changes of fluidity in sexual orientation have considered fluidity in self-reported sexual orientation identity (statements about one's selfidentification as hetero-/bi- or homosexual) in adulthood (Kinnish, Strassberg, \& Turner, 2005; Ott et al., 2011; Scheitle \& Wolf, 2018). Apart from marked developmental differences, it should be noted that most studies on adults have assessed the fluidity of sexual orientation identity (Everett, 2015; Katz-Wise \& Hyde, 2015; Scheitle \& Wolf, 2018) — a construct that likely does not represent first feelings of sexual attraction in adolescents very well (Diamond \& SavinWilliams, 2000; Ott et al., 2011; Perrin, 2002; Rosario et al., 2006; Savin-Williams \& Cohen, 2007; Scheitle \& Wolf, 2018). This finding demonstrates the importance of considering romantic 
and sexual attraction, and sexual orientation identity as two distinct constructs, separated by the developmental sequence and influenced by differential factors.

Although the prevalence of sexual fluidity in adults (i.e., ages $18+$ ) is relatively well documented (e.g., studies assessing outcomes longitudinally, such as the General Social Survey; Scheitle \& Wolf, 2018), longitudinal surveys in adolescence (i.e., ages 13-18) are rare. The AddHealth survey (Hu, Xu, \& Tornello, 2016; Li, Pollitt, \& Russell, 2016; Savin-Williams, Joyner, \& Rieger, 2012; Savin-Williams \& Ream, 2007), and the Growing Up Today Study (GUTS; Katz-Wise et al., 2017; Ott et al., 2011) found that fluidity of sexual orientation identity was higher among young women than men (Ott et al., 2011; Savin-Williams et al., 2012). A third study from New Zealand drawn from a birth cohort (aged 21 to 26 years) found that around 10\% of young adults reported change in sexual attraction over two time points (Dickson, Paul, \& Herbison, 2003). Only the studies by Dickson et al. (2003) and Hu et al. (2016) considered changes in sexual attraction (instead of sexual orientation identity), and none of the studies assessed these changes during a specifically defined period of late or middle adolescence, respectively.

\section{Gender Differences and Sexual Minority Groups}

Some theorists as well as researchers have suggested that young women are more likely than young men to report changes in sexual attraction, but more recently also indicate that fluidity may be similarly common among men (Diamond, 2008, 2016; Diamond \& Rosky, 2016; Everett, 2015; Ott et al., 2011; Savin-Williams et al., 2012). The extent and cause of these possible gender differences, however, remain unclear, appear to be inconsistent (Diamond, 2016), and may be related to a sexual minority status. Although shifts can occur in any direction, stability of sexual orientation identity is usually more prevalent in individuals who consider themselves $100 \%$ heterosexual or $100 \%$ homosexual, than in individuals who report a bisexual or mostly 
hetero-/homosexual identity (Ott et al., 2011; Savin-Williams \& Vrangalova, 2013; Scheitle \& Wolf, 2018).

Overall, females reported higher mobility scores with regard to sexual orientation identity in the study by Ott et al. (2011). However, Ott et al. did not find gender differences when the sample was restricted to only those who reported a minority sexual orientation identity, similar to results presented by Rosario et al. (2006). In contrast, findings from the recent longitudinal study of American adults demonstrated that women and non-heterosexual individuals reported more fluid sexual identity than heterosexual men (Scheitle \& Wolf, 2018). However, these mobility patterns were not examined with regard to sexual attraction in a sample of younger adolescents (cf. Ott et al., 2011), which calls for research on gender differences in fluidity or mobility in this dimension.

\section{Religiosity and Sexual Orientation}

Conservative religious beliefs are often associated with stigma toward sexual minority identities as well as homonegativity (Beaulieu-Prévost \& Fortin, 2015; Olson, Cadge, \& Harrison, 2006). Therefore, the inclusion of religion into demographic research has been recommended by the National Research Council (2011) when assessing sexual minority samples. In their large-scale probability-based U.S. survey, Scheitle and Wolf (2018) explored longitudinally whether adults who both identify as a sexual minority and as a religious person reported more sexual fluidity than heterosexual or non-religious individuals. The study found that, among individuals who were not exclusively heterosexual at baseline, higher levels of religiosity were associated with a higher likelihood of sexual identity fluidity over time. A higher degree of fluidity was likely caused by cognitive dissonance between one's sexual identity and religiosity (Anderton, Pender, \& Asner-Self, 2011; Page, Lindahl, \& Malik, 2013), which could 
potentially lead to a higher likelihood to change one's sexual orientation identity, specifically from hetero- to non-heterosexual (Scheitle \& Wolf, 2018; Wood \& Conley, 2014).

To the best of our knowledge, the relationship between religiosity and the fluidity of sexual attraction has not been assessed longitudinally during middle to late adolescence, a period that is characterized by a higher susceptibility to social norms, peer influence, and expectations (Steinberg \& Morris, 2001), and crucial with regard to long-term sexual development. This enhanced vulnerability may render adolescents more susceptible to changes in sexual attraction (Friedman et al., 2004). Longitudinal explorations over multiple time points are particularly needed to systematically address the role of religion in sexual orientation identity development, especially the dynamics of sexual attraction fluidity among adolescents.

In socioreligious terms, Croatia, a Southeastern European country, provides an interesting context for adolescent sexual development. In the period following the breakup of Yugoslavia in the early 1990s, the country witnessed an increase in religiosity-including its rise among young people (Jerolimov \& Jokić, 2010). This resulted in Croatia becoming one of the most religious countries in Europe (see Luijkx, Halman, Sieben, Brislinger, \& Quandt, 2016), with over 85\% of its citizens identifying as Roman Catholic. In comparison to Roman Catholic countries in the European West and South (Italy, Spain, Portugal, and France), levels of sexual permissiveness appear to be markedly lower in Croatia (Štulhofer \& Rimac, 2009).

\section{The Current Study}

Our study aimed to assess the fluidity of adolescent sexual and romantic attractionwhich here denotes a part of the process of figuring out one's sexual identity and sexual orientation - and explore the role of religiosity in this dynamic using two independent panel samples of Croatian high-school students from large urban settings. Religiosity was conceptualized as a potential (internal) obstacle to expressing non-heterosexual attraction. Due 
to developmental reasons (romantic and sexual attraction precedes personal acknowledgement and, later, disclosure of sexual orientation; Katz-Wise \& Hyde, 2015; Ott et al., 2009), and in line with other research on adolescent sexual orientation (Freidman et al., 2004; Shearer et al., 2018), the present study measured attraction — a facet of sexual orientation — rather than sexual orientation identity. Taking into account conflicting findings on gender differences in the stability of sexual attraction (Dickson, Paul, \& Herbison, 2003; Ott et al., 2011; Katz-Wise, 2015; Rosario et al., 2006), the present study also addressed the question if the dynamic of adolescent sexual and romantic attraction is gender-specific. Additionally, given that there is a dearth of research examining gender differences among adolescents outside of the United States, the present study aimed to contribute to the literature by providing unique insight into possible gender-specific differences in the fluidity of adolescent sexual and romantic attraction among a highly religious culture (Luijkx et al., 2016; World Population Review (Croatia Population), 2018).

\section{METHOD}

The data for this study were collected in two independent panel samples recruited in the Croatian capital city (Zagreb) and the third largest urban setting in the country (Rijeka) as parts of the PROBIOPS (Prospective Biopsychosocial Study of the Effects of Sexually Explicit Material on Young People's Sexual Socialization and Health) project. The two panels enabled a replication of findings. The first and smaller panel (Zagreb; $N=849$ ) is presented first, followed by the second, larger panel (Rijeka; $N=995)$.

\section{Participants and Recruitment}

Zagreb Panel. Second-year students from 59 secondary schools in Zagreb and its county were recruited in April 2015 for an online longitudinal study. Given that romantic and erotic attraction was assessed only at baseline (T1) and the two final waves (T4 and T5), 289 male and 
560 female students who took part in at least two of these three waves were included in the present analyses. In total, the observation period (T1-T5) was approximately 24 months. At baseline $(\mathrm{T} 1)$, the average age in the sample was 16.1 years $(S D=.44)$. The majority $(77.16 \%)$ of participants lived with both parents at the time of the survey. Over a third of participants had a college educated father (40.6\%) and/or mother (42.5\%). While $16.4 \%$ of adolescent girls and boys never attended religious services, $14.3 \%$ reported going to a church several times a month and $16.8 \%$ every week. To compare sociodemographic characteristic and baseline romantic and erotic attraction between selected participants (coded 1) and their peers who were not included in this study (coded 0), a multivariate logistic regression analysis was conducted. Compared to participants who did not complete the necessary two waves of data collection, the adolescents included in this study had significantly higher odds of being female (AOR $=1.63, p<.001$ ), having better grades $(\mathrm{AOR}=1.78, p<.001)$, and more likely to report having an educated father $(\mathrm{AOR}=1.26, p=.01)$. The included and excluded students did not differ significantly in religiosity or the initial romantic and erotic attraction.

Rijeka Panel. Similar to the Zagreb panel, second-year students were recruited at the end of 2015 from 14 schools in Rijeka to participate in a classroom-based longitudinal study. Only students who participated in at least two of the three waves in which the attraction question was asked (T3, T5, and T6) — and thus, 361 male and 634 female students in total—were included in the present analyses. The period of observation spanned 16 months.

On average, participants were $15.8(S D=.48)$ years old at baseline $(\mathrm{T} 1)$. At the time of the survey, $80.7 \%$ of students reported living with both parents. A college educated mother and father were reported by $41.3 \%$ and $37.5 \%$ of the participants, respectively. Personal religiosity was slightly lower compared to the Zagreb panel: $9.2 \%$ of participants attended religious services on a weekly basis and $10.7 \%$ several times a month, while $17.3 \%$ reported no attendance. When 
basic sociodemographic characteristics and the initial attraction (measured at T3) of the selected participants (coded 1) and other in the panel (coded 0) were compared, three significant differences were observed. Participants selected in this study had higher odds of being female $(\mathrm{AOR}=1.93, p<.001)$, having a higher academic achievement $(\mathrm{AOR}=2.11, p<.001)$, and were more likely to report an educated mother $(\mathrm{AOR}=1.63, p=.002)$.

\section{Procedure}

A self-administered online survey was used to collect data in the Zagreb panel. The initial recruitment was conducted by distributing leaflets with a unique code and instruction for onetime online registration among sophomore students in the selected schools. Prospective participants were asked to visit the study website and register using their Facebook account or email address. To compensate for their time, after survey completion, each participant was entered into a lottery for the chance to win a voucher worth $\$ 16.5(13.5 €)$. In Rijeka, pen-and-paper surveying was carried out during class time. To enhance confidentiality, cardboard screens were placed between students. A simple 5-character alphanumeric code was used to link questionnaires across time points. No incentives were offered for participation. In both panels, data collection waves were spaced 5-6 months apart.

Considering that the national guidelines for ethical research in minors stipulate that individuals aged 14 years and older can give informed consent, parents were informed about the study in broad terms but informed consent was asked only of potential participants (at each wave). Contact information for a non-governmental organization that provides counseling was included in all questionnaires.

All study procedures were approved by the Ethical Research Committee of the Faculty of Humanities and Social Sciences, University of Zagreb.

\section{Measures}


Adolescents' sexual and romantic attraction was measured with the following question: "I am attracted to persons..." A five-point scale based on the categorization of the Kinsey scale (Kinsey, Pomeroy, \& Martin, 1948) was used to anchor answers ( $1=$ exclusively of the other sex, $2=$ mostly of the other sex, $3=$ equally of the other and same sex, $4=$ mostly of my sex, $5=$ exclusively of my sex). The indicator had reasonable stability in both panels ( $r_{\text {Zagreb }}=.53-.74$ and $\left.r_{\text {Rijeka }}=.63-70\right)$. In univariate analysis only, the indicator was dichotomized into $0=$ exclusively heterosexual attraction (the original category 1 ) and $1=$ other (categories 2-5).

Religiosity was assessed at baseline, using the standard indicator of the frequency of attending religious ceremonies (“Apart from funerals, weddings, baptisms, etc., how often do you attend religious services?”). Response options ranged from $1=$ never to $6=$ once a week or more often.

\section{Statistical Analysis}

The dynamics of fluidity in adolescent's sexual attraction were explored by latent growth curve modeling (LGCM; Bollen \& Curran, 2006; Duncan, Duncan, \& Strycker, 2011). This relatively new approach measures change over time with (at least) two latent factors: a latent intercept, which indicates baseline levels of the construct of interest, and a latent slope, which represents the trajectory of change. Mean values associated with latent factors signify the average or group-level values, while variance in latent factors indicate individual variation around the average values. This simultaneous assessment of between-individual and withinindividual trajectories of change distinguishes LGCM from older approaches to analyzing repeated observations (Jones, 2012).

In the first step, the linear curve and a non-specified cumulative curve (the first latent slope loading is fixed to 0 and the last to $1 ;$ McArdle \& Grimm, 2010) were compared for fit to 
the data. ${ }^{1}$ According to the standard chi-square difference test for nested models, the more parsimonious model (linear curve) had superior fit in both panels. Next, the full model was built by adding three controls: age, gender, and religiosity. Following standard recommendations (Duncan, Duncan \& Stryker, 2006; Little, 2013), error terms of time-variant sexual and romantic attraction indicators were constrained to equality. The following criteria for good model fit were used (Little, 2013): non-significant chi-square test, CFI values $>.95$ and RMSEA values $<.05$.

Because information about sexual and romantic attraction was, according to Little's test (Zagreb: $\chi^{2}[4]=3.61, p<.46$, and Rijeka: $\chi^{2}[8]=12.02, p<.15$ ), missing completely at random, full information maximum likelihood (FIML) estimation was used to handle missing values (Graham, 2012). To explore possible nestedness of (in)stability in adolescent attraction in schools (Zagreb) or classes (Rijeka), intra-class correlation (ICC) was estimated by panel using unconditional means random effects model. Due to low ICC in either panel $(3.9 \%$ of variance in attraction was explained by schools in the Zagreb panel and 3.5\% by classes in the Rijeka panel), the higher-level effect was ignored in subsequent analyses.

\section{RESULTS}

Table 1 shows basic sociodemographic and sociosexual characteristics of participants in the two panel samples by gender. Most of the sampled female and male adolescents reported no experience of sexual intercourse and parents with a high school education. Given that participants in the Zagreb panel were slightly older than those in the Rijeka panel, the proportion of sexually active participants was somewhat higher in the capital city.

\footnotetext{
${ }^{1}$ For precision, the linear curve was specified in months (in Rijeka, the period between data collection waves ranged from 4.5 to 6 months).
} 
A descriptive analysis of changes in sexual and romantic attraction in the Zagreb and Rijeka panels is presented in Figs. 1 and $2 .^{2}$ The analysis only included adolescents who participated in all three relevant study waves. Exclusively heterosexual attraction at baseline was somewhat higher among adolescent boys than girls in both panels ( $89 \%$ vs. $83 \%$ and $90 \%$ vs. $86 \%$, respectively). The difference was statistically significant in the Zagreb panel $\left(\chi^{2}=7.47, p<\right.$ $.001)$, but not in the Rijeka panel $\left(\chi^{2}=.54, p=.463\right)$. Over time, changes in sexual and romantic attraction were substantially less prevalent among exclusively heterosexual participants compared to other participants. For example, the fluidity among exclusively heterosexually attracted female adolescents from Zagreb was observed in 6-10\% of cases per wave, whereas the respective proportions among those who reported other attractions were $20-23 \%$. Similarly, in the Rijeka sample, fluidity was reported by $3-5 \%$ of exclusively heterosexually attracted and 24$32 \%$ of male adolescents who reported other attractions per wave. The rate of change in attraction fluidity was higher in the first and longer period under observation (T4 to T5 and T5 to T6, respectively).

Stability of attraction, defined as belonging to the same group (i.e., either the exclusively heterosexual attracted or the other attracted one) at the first and the last measurement, was observed in $91.5 \%$ and $96.1 \%$ of exclusively heterosexually attracted adolescents in Zagreb and Rijeka, respectively, and in only $28.5 \%$ and $33.7 \%$ of other attracted adolescents. These between-group differences were substantial (Cramer's $V_{\text {ZAGREB }}=.38$ and $V_{\text {RIJEKA }}=.43$ ) and statistically significant $\left(\chi^{2}\right.$ ZAGREB $=120.30, p<.001 ; \chi^{2}$ RIJEKA $\left.=155.84, p<.001\right)$.

\section{The Dynamics of Adolescents' Sexual and Romantic Attraction}

\footnotetext{
${ }^{2}$ More detailed information about attraction fluidity is available from the corresponding author.
} 
Two unconditional LGC models that represented adolescent sexual and romantic attraction in the Zagreb and Rijeka panels displayed good fit. The following values were obtained for Zagreb: $\chi^{2}(2)=1.93, p=.381 ; \mathrm{CFI}=1.0 ; \mathrm{RMSEA}=.000[90 \% \mathrm{CI}=.000-.067]$. Latent factor means (between-person components) and variances (within-person components) in adolescent attraction were all statistically significant: $M_{\text {intercept }}=1.22$, S.E. $=.02, p<.001$; $\sigma_{\text {intercept }}^{2}=.24$, S.E. $=.02, p<.001 ; M_{\text {slope }}=0.05$, S. E. $=.02 ; p=.012, \sigma^{2}$ slope $=.14$, S.E. $=.03, p$ $<.001$. The positive mean slope pointed to a small but statistically significant increase over time in the proportion of adolescents who reported an attraction that was not exclusively heterosexual. In the Rijeka panel, the model also had good fit $\left(\chi^{2}[2]=.35, p<.83 ; \mathrm{CFI}=1.0\right.$, RMSEA $=.000[90 \% \mathrm{CI}=.000-.036])$. However, while the average level of sexual and romantic attraction at baseline was substantially different from zero $\left(M_{\text {intercept }}=1.19\right.$, S.E. $\left.=.02, p<.001\right)$, with significant individual variation around it $\left(\sigma^{2}\right.$ intercept $=.00$, S.E. $\left.=.00, p<.001\right)$, we found no significant change in adolescent attraction over time, either at the between- or within-individual level $\left(M_{\text {slope }}=.00\right.$, S.E. $=.00, p=.129 ; \sigma^{2}$ slope $=.00$, S.E. $\left.=.00, p=.119\right)$, indicating that the inclusion of conditionals (age, gender, and religiosity) would only make sense for the initial levels of adolescent attraction.

\section{The Role of Gender and Religiosity}

Controlling for participants' age and religiosity, gender was found to significantly predict baseline attraction in the larger sample (Rijeka; $b=0.09$, S. E. $=.03, p=.008$ ); no significant association between gender and the fluidity of attraction was observed in the Zagreb panel. In the case of religiosity, associations with baseline attraction were found in both panels (see Figs. 3 and 4). Compared to their less religious peers, more religious participants in both panels were 
significantly less likely to initially report a non-exclusively heterosexual attraction $(b$ ZAGREB $=-$ 0.07 , S.E. $=.01, p<.001$ and $b_{\text {RIJEKA }}=-0.06$, S.E. $\left.=.01, p<.001\right) .^{3}$

To take into account substantial skewedness in adolescent sexual and romantic attraction, the conditional models were bootstrapped with 5,000 resamples to check the robustness of the few significant associations. The pattern of (non-)significant structural associations was fully confirmed in both panels.

\section{DISCUSSION}

The present longitudinal study carried out in two independent panels of urban Croatian adolescents aimed to assess the stability vs. fluidity, respectively, of adolescent sexual and romantic attraction, and its relationship to personal religiosity and gender over time. We used a LGCM approach to obtain not only between-individual, but also within-individual estimations, which are essential for systematic understanding of the dynamics of sexual orientation development during adolescence.

First, the majority of both female and male participants in both panels were characterized by stable sexual and romantic attraction. Secondly, attraction fluidity was substantially lower among exclusively heterosexually attracted participants, compared to their non-exclusively heterosexual peers. Although both findings are in line with the existing research on sexual fluidity (Everett, 2015; Hu et al., 2016; Ott et al., 2011; Rosario et al., 2006; Savin-William et al., 2012; Savin-Williams \& Ream, 2007; Scheitle \& Wolf, 2018), the observed difference in attraction fluidity might be developmentally specific to adolescents around the age of 16 and up to two

\footnotetext{
${ }^{3}$ Initially, the interaction of gender and religiosity was also included in the models (the two indicator were meancentered before multiplication), but was omitted after failing to reach statistical significance in either panel. The models with the interaction term did not fit the data significantly better from the (more parsimonious) models presented in Figures 2 and 3.
} 
years later. The direction in which adolescents are moving with regard to their sexual orientation identity or attraction may be sensitive to age and should thus not be generalized to other age groups. Thirdly, fluidity in sexual attraction seemed to decrease over time, but the unequal spacing between observation points precludes any conclusions about the relationship between adolescent development and attraction fluidity. Fourthly, the significant, albeit small growth in less exclusively heterosexual attraction over time that was found in the first panel (Zagreb) could not be replicated in the second and somewhat larger panel (Rijeka). Fifthly, religiosity was systematically associated with the initial levels of attraction (but not with its subsequent change in the Zagreb panel), so that more religious adolescents were more likely to report exclusively heterosexual attraction. Finally, the observed gender differences in sexual and romantic attraction were inconsistent (i.e., did not replicate), and of small size. Only in the larger panel, female adolescents reported higher baseline fluidity than their male peers.

\section{Sexual Fluidity in Adolescence}

Questioning one's own sexual and romantic attraction, or a (temporary) fluctuation in attraction, may be part of some young people's developmental process when transitioning from adolescence into emerging adulthood (Friedman et al., 2004; Austin, Conron, Patel, \& Freedner, 2007). The present study confirms that fluidity in sexual attraction is present in a minority of Croatian adolescents aged 16 to 18 years, when assessed over multiple times points. Similar to the results from AddHealth reported by Xu et al. (2016), stability of both non-heterosexual and heterosexual attraction increased in the period between the first and the last measurement, which is also in line with the longitudinal studies of emerging adults (Ott et al., 2011), and adults (Scheitle \& Wolf, 2018). Although the unequal spacing of survey waves in which romantic and sexual attraction was assessed does not allow conclusions about the rate of change in attraction and its relation to other possible developmental factors, the present study supports the notion that, 
for a substantial proportion of young people, the development of sexual attraction is a gradual (but not necessarily linear) process.

\section{Sexual Fluidity and Religiosity}

Although in the present study no significant association between religiosity and changes in adolescent romantic and sexual attraction over time was found, more religious adolescents were more likely to report exclusively heterosexual attraction at baseline. This suggests that a strong religious identity may delay the coming-out process for sexual minority adolescents or that there are other factors that may explain changes in adolescents' sexual attraction over time. This lack of association between religiosity and change in attraction is different than research findings from adult samples (Scheitle \& Wolf, 2018).

\section{Gender Differences}

Same-gender or non-exclusively heterosexual attractions were generally more common among female than male adolescents, but the baseline difference was significant only in the Zagreb panel. This finding is in line with many studies that focused on gender and sexual development in adolescents, emerging adults, and adults (Dickson, Van Roode, Cameron, \& Paul, 2013; Hu et al., 2016; Ott et al., 2011; Savin-Williams \& Ream, 2007; Scheitle \& Wolf, 2018). Similar to this study's results, data on sexual minority youth from the large representative survey by Katz-Wise et al. (2017) showed a significantly higher prevalence of same-sex sexual attraction in female than in male youth. The societal norms around gender and sexuality, as well as sexualized popular media presentations, may result in young women engaging more often in same-sex sexual behaviour than young men. However, some studies failed to observe genderspecific differences in changes of sexual attraction and sexual orientation identity among young adults (Katz-Wise, 2015) — which was also the case with the current study (gender was not significantly associated with changes in attraction over time) — suggesting that the relationship 
between gender and the development of sexual orientation is still not fully understood. The fact that several studies have sampled participants in different developmental phases, with ages ranging from 12 to 25 years (Ott et al., 2011), is a further complication. Future studies should focus on a narrower age range, which is consistent with literature on sexual development milestones, and include a longer observation period.

\section{Strengths and Limitations}

This study has several strengths, including two reasonably large independent panels, which enabled replication of findings - a practice sorely neglected in social sciences (Freese, 2007; Koole \& Lakens, 2012; Schmidt, 2009) — the use of a robust analytical approach (LGCM), and a relatively lengthy period under observation (16 and 24 months). At the same time, the time of observation was clearly defined, and focused on middle and late adolescence (from around 16 to 18 years of age). Developmentally, the period under observation may be particularly relevant for observing changes in sexual attraction, which have been found to precede changes in sexual orientation identity that take place in late adolescence and emerging adulthood (see Ott et al., 2011).

The first limitation of this study is related to the fact that only one dimension, namely sexual attraction, of sexual orientation was measured, which is a multi-faceted and not necessarily highly congruent construct (Diamond, 2000; Hu et al., 2016). Considering that our participants were between 16 and 17 years of age at the onset of the study, we believe that it was developmentally appropriate, although analytically limiting, to focus on sexual and romantic attraction.

Another limitation is related to the assessment of only three time points used in this study. It has been argued that the measurement of sexual fluidity may be highly sensitive to the number and the timing of observations (Ott et al., 2011; Scheitle \& Wolf, 2018). Thus, a more robust and 
insightful longitudinal approach to measuring fluidity in adolescent sexual and romantic attraction would require a larger number of observations (which would enable more precise estimations of latent growth trajectories of attraction) spaced at equal intervals. In addition, the dichotomization of attraction presented in Figures 1 and 2 masked the fluidity within the nonexclusively heterosexually attracted group. Such analytical approach cannot distinguish between a person who, for example, reported mostly heterosexual attraction at the first measurement but exclusively same-sex attraction at the last measurement, and someone who reported exclusively same-sex attraction at the first and then bisexual attraction at the final measurement. This is, however, limited to the descriptive part of our study. The more analytical part (presented in Figures 3 and 4) explored the fluidity by taking into account the full range of adolescents' attractions.

Finally, our study's findings are likely culture-specific, although the extent of this remains unknown. Croatia is a highly religious country (Luijkx et al., 2016; World Population Review [Croatia Population], 2018) with increasing social and political power of the local Roman Catholic Church. This rising influence has been reflected in recent culture wars over same-sex marriage, school-based sexuality education, and "gender ideology," making youth sexuality a highly sensitive topic (Hodžić \& Štulhofer, 2017; Kuštreba, Elezović, \& Štulhofer, 2015). According to very limited evidence, so far these changes seem to have affected young people's sexual behavior in a very limited way (Puzek, Štulhofer, \& Božičević, 2012). It is possible that the available estimates of adolescents' attraction fluidity have been biased by social desirability. Non-heterosexual adolescents may experience heteronormative pressure and decide against disclose their true attraction, which would bias the fluidity downward. With age, the impact of social desirability may weaken — which would result in a seeming increase in attraction fluidity. 
To minimize this validity threat, multiple steps were taken to decrease the effect of social desirability by maximizing participants' confidentiality and anonymity.

Adolescence is a crucial time period for the long-term development of sexual attraction and our findings corroborate insights that developmental pathways are different for adolescents characterized with a non-heterosexual attraction, compared to their exclusively heterosexually attracted peers (Savin-Williams \& Vrangalova, 2013). According to our findings, individuals who reported a non-exclusively heterosexual attraction displayed substantially more fluidity during the time period under observation. In addition, for sexual minority individuals with strong religious beliefs or identity, the development of sexual orientation identity may be prolonged due to an internal conflict between their attraction/desire and religious values (Dahl \& Galliher, 2012, Levy \& Reeves, 2011; Scheitle \& Wolf, 2018; Schuck \& Liddle, 2001). This internal conflict can negatively impact mental health of sexual minority adolescents (e.g., Li, Pollitt, \& Russell, 2016; Olson et al., 2006). Consequently, for mental health professionals working with sexual minorities, it is important to better understand ways that one's religious identity may promote or hinder psychosocial well-being. This study's findings have relevance for teachers, parents, and counselors working with adolescents, especially adolescents who experience a sexual orientation or identity that is considered non-heterosexual or non-normative. 


\section{REFERENCES}

Anderton, C. L., Pender, D. A., \& Asner-Self, K. K. (2011). A review of the religious identity/sexual orientation identity conflict literature: Revisiting festinger's cognitive dissonance theory. Journal of LGBT Issues in Counseling. https://doi.org/10.1080/15538605.2011.632745

Austin, S. B., Conron, K., Patel, A., \& Freedner, N. (2007). Making sense of sexual orientation measures: Findings from a cognitive processing study with adolescents on health survey questions. Journal of LGBT Health Research, 3(1), 55-65.

Beaulieu-Prévost, D., \& Fortin, M. (2015). The measurement of sexual orientation: Historical background and current practices. Sexologies, 24(1), e15-e19. https://doi.org/10.1016/j.sexol.2014.05.006

Bollen, K. A., \& Curran, P. J. (2006). Latent curve models: A structural equation perspective. Hoboken, NJ: Wiley.

Dahl, A. L., \& Galliher, R. V. (2012). LGBTQ adolescents and young adults raised within a Christian religious context: Positive and negative outcomes. Journal of Adolescence, 35(6), 1611-1618. https://doi.org/10.1016/j.adolescence.2012.07.003

Diamond, L. M. (2000). Sexual identity, attractions, and behavior among young sexual-minority women over a 2-year period. Developmental Psychology, 36(2), 241-250. https://doi.org/10.1037/0012-1649.36.2.241

Diamond, L. M. (2003). What does sexual orientation orient? A biobehavioral model distinguishing romantic love and sexual desire. Psychological Review, 110(1), 173-192. https://doi.org/10.1037/0033-295X.110.1.173

Diamond, L. M. (2008). Female bisexuality from adolescence to adulthood: Results from a 10year longitudinal study. Developmental Psychology, 44(1), 5-14. 
https://doi.org/10.1037/0012-1649.44.1.5

Diamond, L. M. (2016). Sexual fluidity in male and females. Current Sexual Health Reports, $8(4), 249-256$.

Diamond, L. M., \& Rosky, C. J. (2016). Scrutinizing immutability: Research on sexual orientation and US legal advocacy for sexual minorities. The Journal of Sex Research, 53(45), 363-391.

Diamond, L. M., \& Savin-Williams, R. C. (2000). Explaining diversity in the development of same-sex sexuality among young women. Journal of Social Issues, 56(2), 297-313. https://doi.org/10.1111/0022-4537.00167

Dickson, N., Paul, C., \& Herbison, P. (2003). Same-sex attraction in a birth cohort: Prevalence and persistence in early adulthood. Social Science and Medicine, 56(8), 1607-1615. https://doi.org/10.1016/S0277-9536(02)00161-2

Dickson, N., Van Roode, T., Cameron, C., \& Paul, C. (2013). Stability and change in same-sex attraction, experience, and identity by sex and age in a New Zealand birth cohort. Archives of Sexual Behavior, 42(5), 753-763. https://doi.org/10.1007/s10508-012-0063-z

Duncan, T. E., Duncan, S. C., \& Strycker, L. A. (2011). An introduction to latent variable growth curve modeling. London: Routledge. https://doi.org/10.4324/9780203879962

Everett, B. (2015). Sexual orientation identity change and depressive symptoms: A longitudinal analysis. Journal of Health and Social Behavior, 56(1), 37-58.

https://doi.org/10.1177/0022146514568349

Freese, J. (2007). Replication standards for quantitative social science: Why not sociology? Sociological Methods and Research, 36(2), 153-172. https://doi.org/10.1177/0049124107306659

Friedman, M. S., Silvestre, A. J., Gold, M. A., Markovic, N., Savin-Williams, R. C., Huggins, J., 
\& Sell, R. L. (2004). Adolescents define sexual orientation and suggest ways to measure it. Journal of Adolescence, 27(3), 303-317.

Graham, J. W. (2012). Multiple Imputation with Norm 2.03. In Missing data: Analysis and design (pp. 73-94). New York, NY: Springer New York. https://doi.org/10.1007/978-14614-4018-5_3

Hodžić, A., \& Štulhofer, A. (2017). Embryo, teddy bear-centaur and the constitution: Mobilizations against "gender ideology" and sexual permissiveness in Croatia. In R. Kuhar \& D. Paternotte (Eds.), Anti-gender campaigns in Europe: Mobilizing against equality (pp. 59-78). London, UK: Rowman \& Littlefield.

Hu, Y., Xu, Y., \& Tornello, S. L. (2016). Stability of self-reported same-sex and both-sex attraction from adolescence to young adulthood. Archives of Sexual Behavior, 45(3), 651659. https://doi.org/10.1007/s10508-015-0541-1

Jerolimov, M.D., \& Jokić, B. (2010). Religion and youth in Croatia. In G. Giordan (Ed.), Annual review of the sociology of religion, Volume 1: Youth and religion. Leiden: Brill.

Katz-Wise, S. L. (2015). Sexual fluidity in young adult women and men: Associations with sexual orientation and sexual identity development. Psychology and Sexuality, 6(2), 189208. https://doi.org/10.1080/19419899.2013.876445

Katz-Wise, S. L., \& Hyde, J. S. (2015). Sexual fluidity and related attitudes and beliefs among young adults with a same-gender orientation. Archives of Sexual Behavior, 44(5), 14591470. https://doi.org/10.1007/s10508-014-0420-1

Katz-Wise, S. L., Rosario, M., Calzo, J. P., Scherer, E. A., Sarda, V., \& Austin, S. B. (2017). Endorsement and timing of sexual orientation developmental milestones among sexual minority young adults in the Growing Up Today Study. Journal of Sex Research, 54(2), 172-185. https://doi.org/10.1080/00224499.2016.1170757 
Kinnish, K. K., Strassberg, D. S., \& Turner, C. W. (2005). Sex differences in the flexibility of sexual orientation: A multidimensional retrospective assessment. Archives of Sexual Behavior, 34(2), 173-183. https://doi.org/10.1007/s10508-005-1795-9

Kinsey, A. C., Pomeroy, W. B., \& Martin, C. E. (1948). Sexual behavior in the human male. Philadelphia, PA: Saunders.

Koole, S. L., \& Lakens, D. (2012). Rewarding replications: A sure and simple way to improve psychological science. Perspectives on Psychological Science, 7(6), 608-614. https://doi.org/10.1177/1745691612462586

Kuštreba, I., Elezović, I., \& Štulhofer, A. (2015). Parents’ attitudes about school-based sex education in Croatia. Sexuality Research and Social Policy, 12(4), 323-334. https://doi.org/10.1007/s13178-015-0203-z

Levy, D. L., \& Reeves, P. (2011). Resolving identity conflict: Gay, lesbian, and queer individuals with a Christian upbringing. Journal of Gay and Lesbian Social Services, 23(1), 53-68. https://doi.org/10.1080/10538720.2010.530193

Li, G., Pollitt, A. M., \& Russell, S. T. (2016). Depression and sexual orientation during young adulthood: Diversity among sexual minority subgroups and the role of gender nonconformity. Archives of Sexual Behavior, 45(3), 697-711. https://doi.org/10.1007/s10508-015-0515-3

Little, T. D. (2013). Longitudinal structural equation modeling. New York: Guilford Press. Luijkx, R., Halman, L., Sieben, I., Brislinger, E., \& Quandt, M. (2016). European values in numbers. Leiden: Brill. https://doi.org/10.1163/9789004328525

McArdle, J. J., \& Grimm, K. J. (2010). Five steps in latent curve and latent change score modeling with longitudinal data. In K. van Montfort, J. Oud, \& A. Sattora (Eds.), Longitudinal research with latent variables (pp. 245-273). New York: Springer. 
https://doi.org/10.1007/978-3-642-11760-2_8

National Research Council. (2011). Reference manual on scientific evidence third ed. Washington, (DC): National Academies Press.

Olson, L. R., Cadge, W., \& Harrison, J. T. (2006). Religion and public opinion about same-sex marriage. Social Science Quarterly, 87(2), 340-360. https://doi.org/10.1111/j.1540$6237.2006 .00384 . \mathrm{x}$

Ott, M. Q., Corliss, H. L., Wypij, D., Rosario, M., \& Austin, S. B. (2011). Stability and change in self-reported sexual orientation identity in young people: Application of mobility metrics. Archives of Sexual Behavior, 40(3), 519-532. https://doi.org/10.1007/s10508-010-9691-3

Page, M. J. L., Lindahl, K. M., \& Malik, N. M. (2013). The role of religion and stress in sexual identity and mental health among lesbian, gay, and bisexual youth. Journal of Research on Adolescence, 23(4), 665-677. https://doi.org/10.1111/jora.12025

Perrin, E. C. (2002). Sexual orientation in child and adolescent health care. New York: Springer.

Puzek, I., Štulhofer, A., \& Božičević, I. (2012). Is religiosity a barrier to sexual and reproductive health? Results from a population-based study of young Croatian adults. Archives of Sexual Behavior, 41(6), 1497-1505. https://doi.org/10.1007/s10508-012-9924-8

Rosario, M., Schrimshaw, E. W., Hunter, J., \& Braun, L. (2006). Sexual identity development among lesbian, gay, and bisexual youths: Consistency and change over time. Journal of Sex Research, 43(1), 46-58. https://doi.org/10.1080/00224490609552298

Savin-Williams, R. C., \& Cohen, K. M. (2007). Development of same-sex attracted youth. In I. Meyer \& M. Northridge (Eds.), The health of sexual minorities (pp. 27-47). Springer, Boston. MA. https://doi.org/10.1007/978-0-387-31334-4_2

Savin-Williams, R. C., \& Diamond, L. M. (2000). Sexual identity trajectories among sexualminority youths: Gender comparisons. Archives of Sexual Behavior, 29(6), 607-627. 
https://doi.org/10.1023/A:1002058505138

Savin-Williams, R. C., Joyner, K., \& Rieger, G. (2012). Prevalence and stability of self-reported sexual orientation identity during young adulthood. Archives of Sexual Behavior, 41, 103110. https://doi.org/10.1007/s10508-012-9913-y

Savin-Williams, R. C., \& Ream, G. L. (2007). Prevalence and stability of sexual orientation components during adolescence and young adulthood. Archives of Sexual Behavior, 36(3), 385-394. https://doi.org/10.1007/s10508-006-9088-5

Savin-Williams, R. C., \& Vrangalova, Z. (2013). Mostly heterosexual as a distinct sexual orientation group: A systematic review of the empirical evidence. Developmental Review, 33(1), 58-88. https://doi.org/10.1016/j.dr.2013.01.001

Scheitle, C. P., \& Wolf, J. K. (2018). Religion and sexual identity fluidity in a national threewave panel of U.S. adults. Archives of Sexual Behavior, 47(4), 1085-1094. https://doi.org/10.1007/s10508-017-0979-4

Schmidt, S. (2009). Shall we really do it again? The powerful concept of replication is neglected in the social sciences. Review of General Psychology, 13(2), 90-100. https://doi.org/10.1037/a0015108

Schuck, K. D., \& Liddle, B. J. (2001). Religious conflicts experienced by lesbian, gay, and bisexual individuals. Journal of Gay \& Lesbian Psychotherapy, 5(2), 63-82. https://doi.org/10.1300/J236v05n02_07

Shearer, A., Russon, J., Herres, J., Wong, A., Jacobs, C., Diamond, G. M., \& Diamond, G. S. (2018). Religion, sexual orientation, and suicide attempts among a sample of suicidal adolescents. Suicide and Life-Threatening Behavior, 48(4), 431-437. https://doi.org/10.1111/sltb.12372

Steinberg, L., \& Morris, A. S. (2001). Adolescent development. Annual Review of Psychology, 
52(1), 83-110. https://doi.org/10.1146/annurev.psych.52.1.83

Štulhofer, A., \& Rimac, I. (2009). Determinants of homonegativity in Europe. Journal of Sex Research, 46(1), 24-32. https://doi.org/10.1080/00224490802398373

Wood, A. W., \& Conley, A. H. (2014). Loss of religious or spiritual identities among the LGBT population. Counseling and Values, 59(1), 95-111. https://doi.org/10.1002/j.2161007X.2014.00044.X

World Population Review (Croatia Population). (2018). Retrieved August 8, 2018, from http://worldpopulationreview.com/countries/croatia-population/ 
Figure 1 - Stability of Sexual and Romantic Attraction among Adolescents in the Zagreb Panel

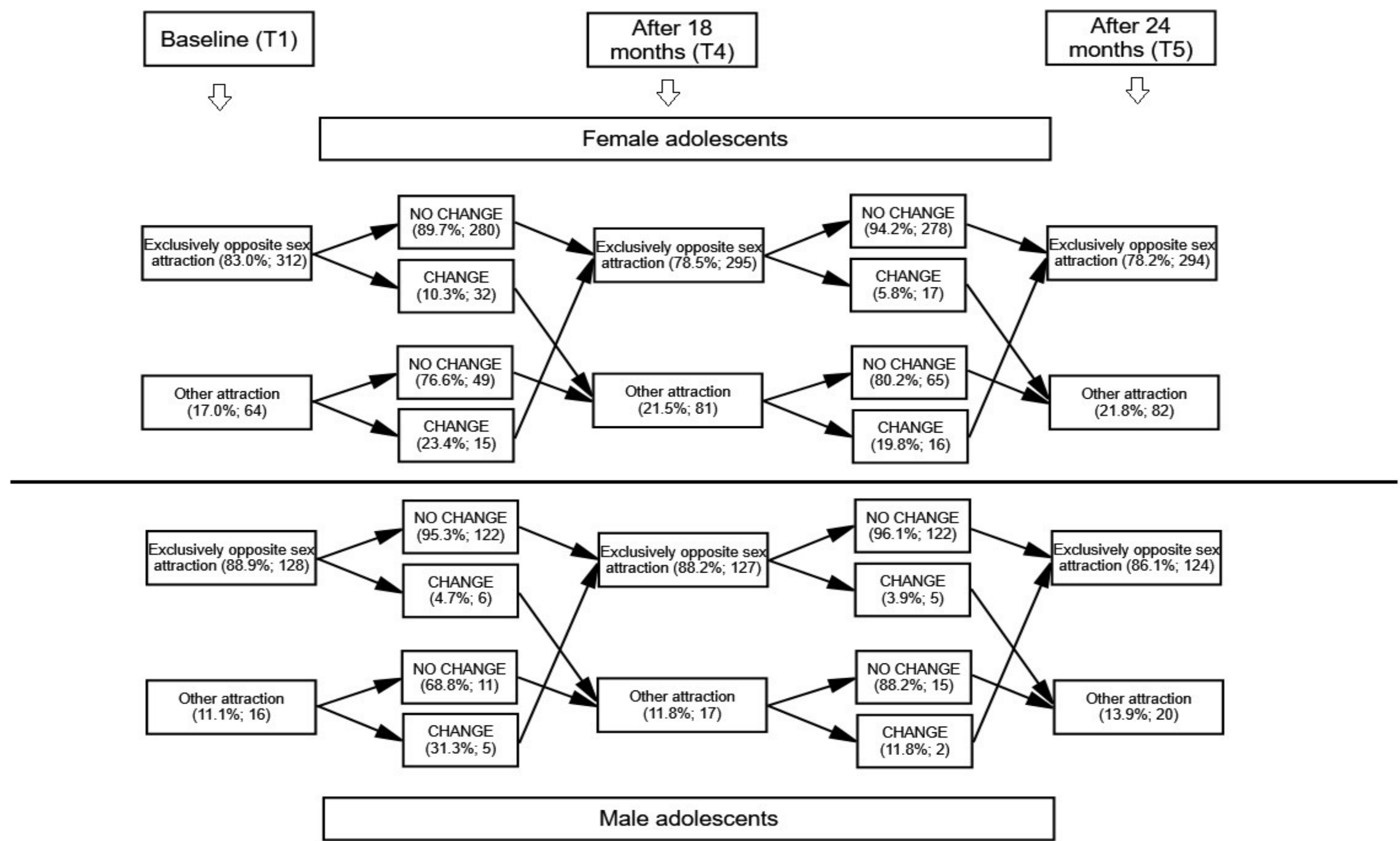

Notes. Only students who participated in all three waves were included. 
Figure 2 - Stability of Sexual and Romantic Attraction among Adolescents in the Rijeka Panel

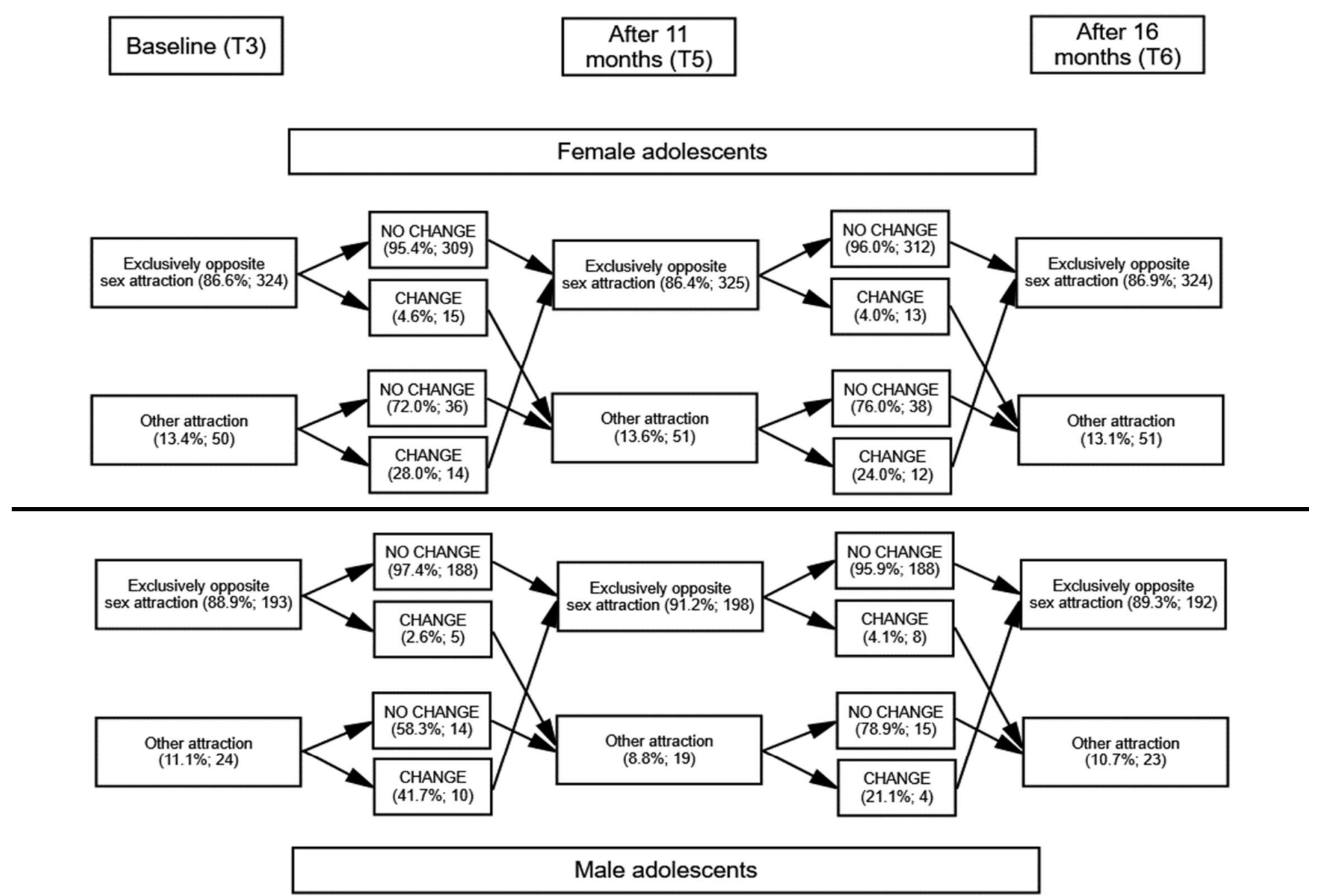

Notes. Only students who participated in all three waves were included; some numbers do not add up due to missing information 
Figure 3 - Predictors of the Stability of Sexual and Romantic Attraction among Adolescents in the Zagreb Panel

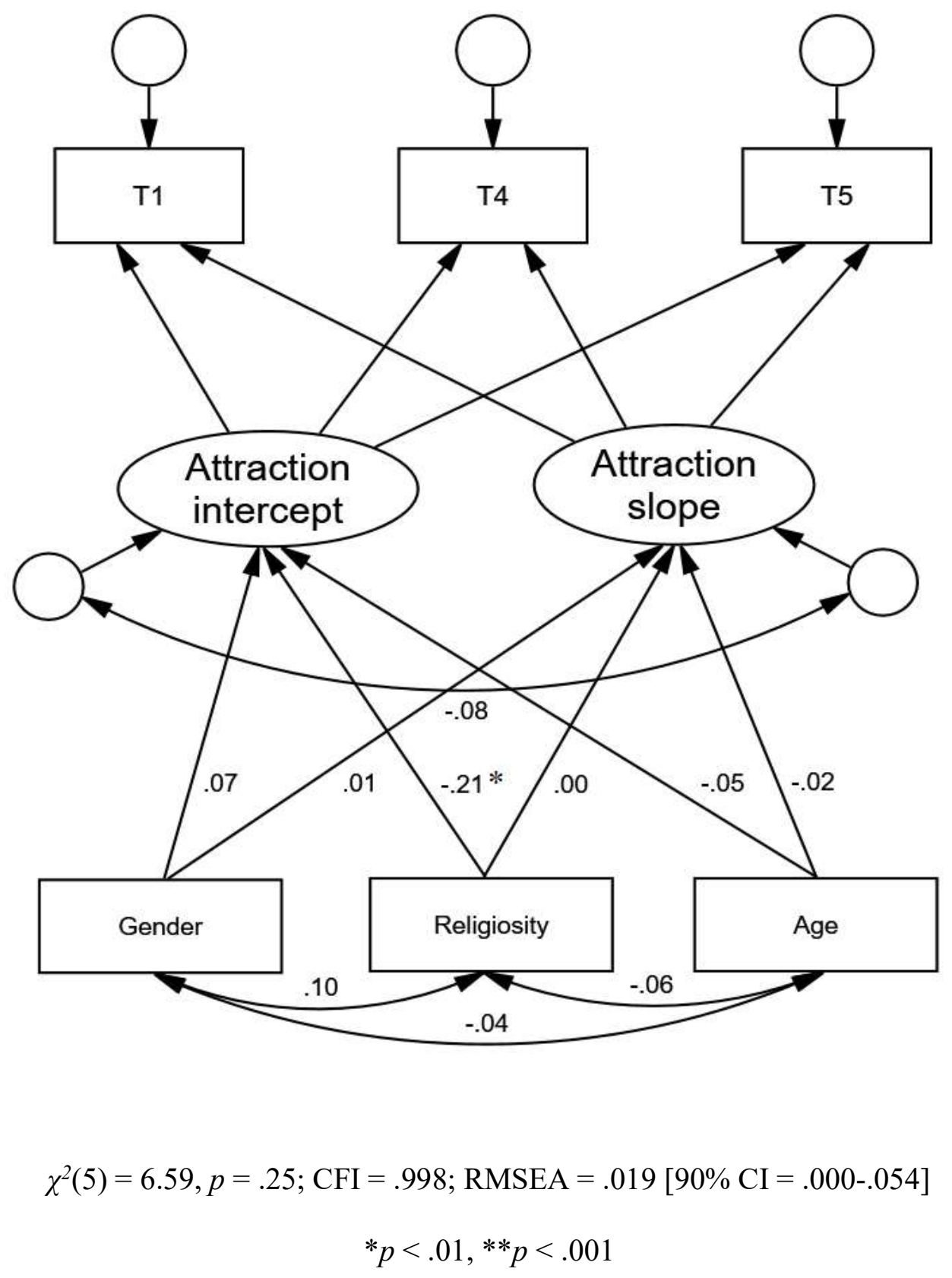

Standardized path coefficients are presented 
Figure 4 - Predictors of the Stability of Sexual and Romantic Attraction among Adolescents in the Rijeka Panel

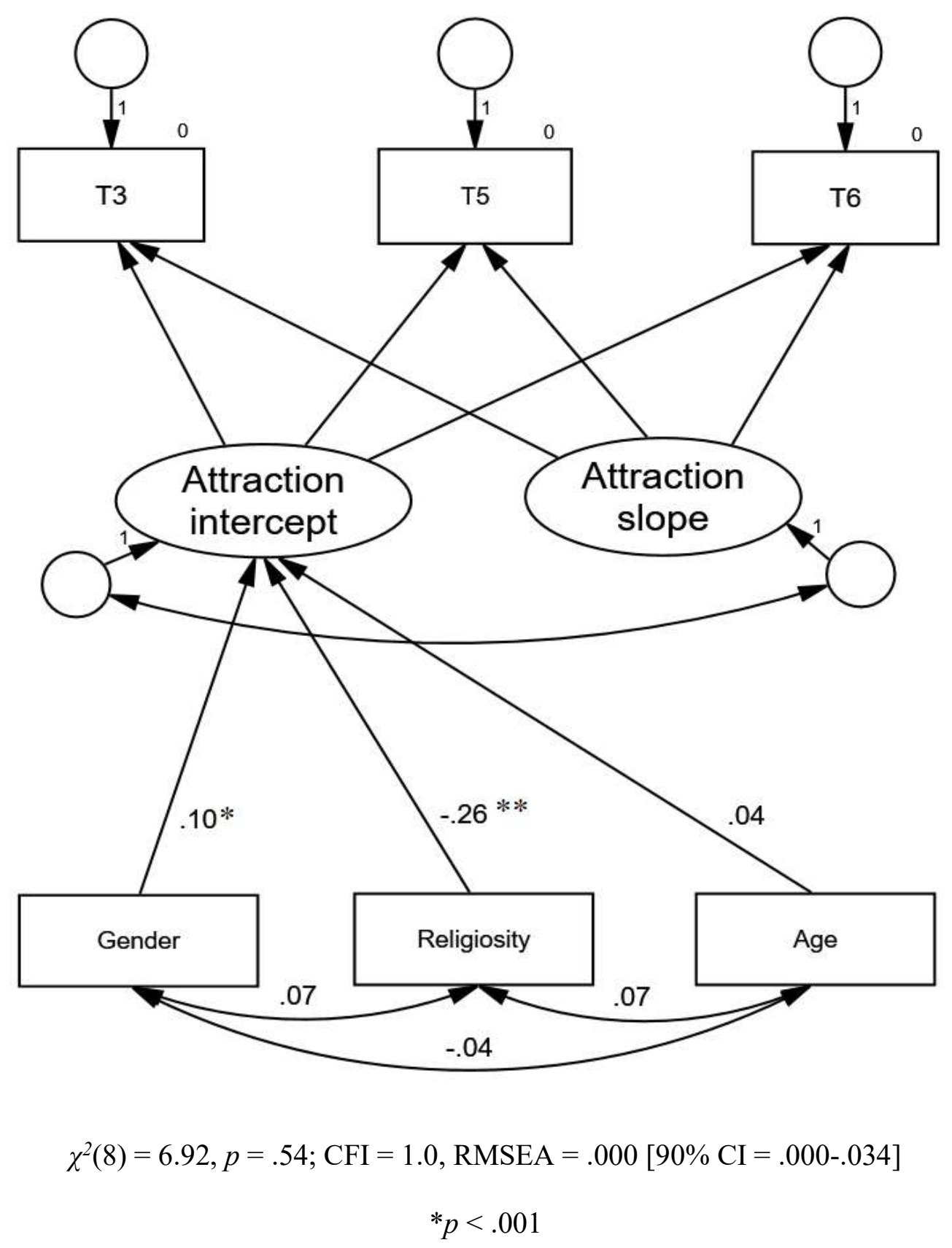

Standardized path coefficients are presented 
Table 1 - Baseline Sociodemographic and Sociosexual Characteristics of Participants in the Zagreb and Rijeka panel samples (by gender)

\begin{tabular}{|c|c|c|c|c|}
\hline & \multicolumn{2}{|c|}{ Zagreb } & \multicolumn{2}{|c|}{ Rijeka } \\
\hline & $\begin{array}{l}\text { Male adolescents } \\
\qquad(n=289)\end{array}$ & $\begin{array}{l}\text { Female adolescents } \\
\qquad(n=560)\end{array}$ & $\begin{array}{l}\text { Male adolescents } \\
\qquad(n=361)\end{array}$ & $\begin{array}{l}\text { Female adolescents } \\
\qquad(n=634)\end{array}$ \\
\hline & $M(S D)$ & $M(\mathrm{SD})$ & $M(\mathrm{SD})$ & $M(\mathrm{SD})$ \\
\hline Age & $16.2(0.49)$ & $16.1(9.41)$ & $15.8(0.48)$ & $15.8(0.49)$ \\
\hline & $n(\%)$ & $n(\%)$ & $n(\%)$ & $n(\%)$ \\
\hline \multicolumn{5}{|l|}{ Father's education } \\
\hline Primary & $9(3.1)$ & $21(3.8)$ & $5(1.7)$ & $13(2.4)$ \\
\hline Secondary & $150(52.1)$ & $321(57.8)$ & $173(57.9)$ & $330(61.1)$ \\
\hline Tertiary & $129(44.8)$ & $213(38.4)$ & $121(40.5)$ & $197(36.5)$ \\
\hline \multicolumn{5}{|l|}{ Mother's education } \\
\hline Primary & $13(4.5)$ & $35(6.3)$ & $6(2.0)$ & $22(4.0)$ \\
\hline
\end{tabular}




\begin{tabular}{|c|c|c|c|c|}
\hline Secondary & $142(49.1)$ & $298(53.3)$ & $153(50.8)$ & $316(57.8)$ \\
\hline Tertiary & $134(46.4)$ & $226(40.4)$ & $142(47.2)$ & $209(38.2)$ \\
\hline \multicolumn{5}{|l|}{ Attending religious ceremonies (religiosity) } \\
\hline Never & $59(20.4)$ & $80(14.3)$ & $60(19.9)$ & $87(15.9)$ \\
\hline Up to several times a year & $138(47.8)$ & $152(45.0)$ & $170(56.3)$ & $302(55.2)$ \\
\hline Up to several times a month & $52(18.0)$ & $125(22.4)$ & $50(16.5)$ & $102(18.7)$ \\
\hline Once a week or more often & $40(13.8)$ & $103(18.4)$ & $22(7.3)$ & $56(10.2)$ \\
\hline \multicolumn{5}{|l|}{ Attracted to persons: ${ }^{\mathrm{a}}$} \\
\hline Exclusively of the other sex & $261(90.3)$ & $467(83.4)$ & & \\
\hline Mostly of the other sex & $15(5.2)$ & $62(11.1)$ & & \\
\hline Both of the other and same sex & $6(2.1)$ & $26(4.6)$ & & \\
\hline Mostly of the same sex & $3(1.0)$ & $3(0.5)$ & & \\
\hline Exclusively of the same sex & $4(1.4)$ & $2(0.4)$ & & \\
\hline \multicolumn{5}{|l|}{ Had sexual intercourse } \\
\hline No & $227(78.5 \%)$ & $485(86.6)$ & $257(84.8)$ & $451(82.8)$ \\
\hline Yes & $62(21.5 \%)$ & 75 (13.4) & $46(15.2)$ & $94(17.2)$ \\
\hline
\end{tabular}

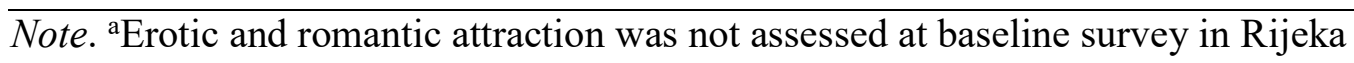

